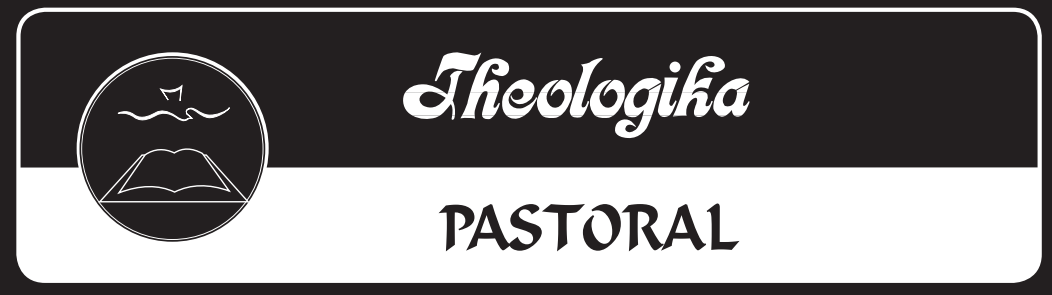

\title{
La Predicación como Diálogo: cómo comunicar la Palabra de Dios de una manera efectiva
}




\section{Derek Morris}




\section{RESUMEN}

\section{“La Predicación como Diálogo: Cómo comunicar la Pala-}

bra de Dios de una manera efectiva" - A través de toda la historia sagrada, Dios se reveló a sí mismo como una persona que habla. En la mayoría de esas instancias Dios al hablar, invitaba a sus oyentes, a participar en la conversación puesto que sin un diálogo, entre el expositor y el oyente, no hay una verdadera comunicación. Los evangelios registran que la predicación de Jesús era eminentemente participativa con sus oyentes; a él le encantaba dialogar con sus oyentes. Los apóstoles siguieron el mismo método, en la exposición del mensaje evangélico, y la iglesia primitiva continuó con la misma dinámica comunicativa. En la actualidad, los predicadores de la Palabra, debieran de buscar la manera de involucrar más a sus oyentes, a fin de que el entendimiento de ella sea más efectivo.

\section{ABSTRACT}

\section{"Preaching as Dialog: How to Communicate the Word} of God in an Effective Manner" - Throughout sacred history, God revealed himself as a speaking person. In most of these instances when God speaks he invited his listeners to join the conversation since without a dialogue between the speaker and the listener there is no real communication. The gospels record that Jesus' preaching was highly participatory with their listeners; he loved to dia$\log$ with their listeners. The apostles followed the same method in exposing the Gospel message and the early church continued with the same communicative dynamics. Today preachers of the Word should look for ways to involve more their listeners in order that the understanding of it should be more effective. 


\section{LA PREDICACIÓN COMO DIÁLOGO: CÓMO COMUNICAR LA PALABRA DE DIOS DE UNA MANERA EFECTIVA}

A lo largo de toda la historia sagrada, Dios se reveló a sí mismo como una persona que habla. Él habló en la creación del universo (Gen. 1:3-26; Sal 33:6, 9). Durante el período del Antiguo Testamento, Dios habló "muchas veces y de diferentes maneras" (Heb 1:1). El verbo hebreo qara' es usado cuando Dios habla, cuando Dios comunica su palabra a través de los profetas, y cuando las personas entran en diálogo personal con Dios. Por ejemplo, qara' se utiliza al señalar que "el Señor proclamó a través de los profetas anteriores" (Zac 7:7), cuando Jeremías es llamado por el Señor para "proclamar las palabras que yo te diga" (Jer 19:2; 2:2), cuando a Jonás se le indica "ve a la gran ciudad de Nínive y proclama en ella el mensaje que yo te doy" (Jon 3:2), y de la venida del Mesías que iba a "proclamar libertad a los cautivos" (Isa 61:1). El verbo qara' es usado también en el diálogo personal de Dios cuando Abraham llamó el nombre Dios (Gén 12:8), cuando el ángel del Señor "llamó a Abraham desde el cielo" (22:15), cuando David oró "respóndeme cuando yo te llame" (Sal 4:1), y cuando David imploró "a ti clamaré oh Señor. Roca mía, no te desatiendas de mí" (8:1). En todo este hablar, los contextos sugieren la expectativa de un diálogo, no simplemente un monólogo.

Amos Wilder observa: "El carácter de la religión, tal como aparece en el Antiguo y el Nuevo Testamento, 
hace del diálogo una forma inevitable de expresión retórica. Dios es conocido como alguien que habla, dirige la palabra, llama, inicia acuerdos y convenios, se involucra en los ensayos de escena pública, así como uno que invita a conversar en entendimiento mutuo". ${ }^{1}$ En repetidas ocasiones, Dios muestra su deseo, tanto a través de los profetas como directamente, de entrar en diálogo con su pueblo. ${ }^{2}$

Según Thompson y Bennett, "El diálogo, como una forma de culto, fue una temprana parte del ritual hebreo, especialmente en algunos de los salmos que, aparentemente, eran dichos, cantados, o entonados antifonalmente en el templo o en el culto de la sinagoga". ${ }^{3}$ Durante el período intertestamentario, las sinagogas emergieron como centros locales de culto y la instrucción. Yngve Brilioth hace esta observación: "Es en el servicio de la sinagoga que el sermón judío asume su forma". ${ }^{4}$

La lectura de la Escritura y la exposición de ella eran partes del servicio, junto con las repeticiones litúr-

${ }^{1}$ Amos N. Wilder, Early Christian Rhetoric: The Language of the Gospel (London: SCM Press, 1964), 52.

${ }^{2}$ Vemos un ejemplo de este diálogo en el Monte Carmelo, donde el profeta Elías llamó a la gente para entrar en diálogo, no solo con él mismo, sino con Dios. Él los desafió con una pregunta: “¿Hasta cuándo van a seguir indecisos entre dos pensamientos? Si Jehová es Dios, seguidle; pero si Baal es Dios, id en pos de él" (1 Rey 18:21). Esto no fue un monólogo profético. Elías estaba invitando al diálogo. Estaba llamando para que dieran una respuesta.

${ }^{3}$ William D. Thompson and Gordon C. Bennett, Dialogue Preaching: The Shared Sermon (Valley Forge, PA: Judson Press, 1969), 16.

${ }^{4}$ Yngve Brilioth, A Brief History of Preaching, trans. Karl E. Mattson (Philadelphia: Fortress Press, 1965): 2. 
gicas, oraciones y bendiciones.. . . La ley y los profetas eran leídos en el día sábado. Cuando el hebreo dejó de ser el lenguaje hablado, se precisó de una interpretación como un suplemento a la lectura. Aunque esta interpretación podía ser ampliada en una exposición detallada y, por lo general, esta asumió el carácter de una charla más bien informal. Así se originó el sermón en la sinagoga. ${ }^{5}$

George Swank señala: “Se esperaba que preguntas, de parte de las congregaciones, formaran una parte de la situación de predicación" ${ }^{6}$ No sólo se favorecía el diálogo, sino que, con el permiso del jefe de la sinagoga, cualquier miembro tenía la libertad de levantarse y dirigir la palabra al grupo. ${ }^{7}$ Brilioth señala: "la exposición de la Escritura no era un privilegio asignado a ningún oficio específico. Esta podía ser delegada a cualquier persona que tuviera la capacidad para ello". ${ }^{\text {. }}$

Encontramos ilustrado este proceso en la visita de Pablo y Bernabé a la sinagoga de Antioquía de Pisidia. Lucas registra que "después de leer la Ley y los Profetas, los dirigentes de la sinagoga les dirigieron la palabra diciendo, 'hermanos si ustedes tienen algún mensaje de ánimo para el pueblo, por favor hablen'” (Hech 13:15).

${ }^{5} I b i d, 4-5$.

${ }^{6}$ George W. Swank, Dialogic Style in Preaching (Valley Forge: The Judson Press, 1981), 47.

${ }^{7}$ Esta práctica hizo posible que Jesús y los primeros predicadores cristianos dirigieran la palabra a los fieles reunidos en varias sinagogas. Ver Mat 4:23; Mar 1:39; Luc 4:15; Hech 14: 1; $18: 4$.

${ }^{8}$ Brilioth, A Brief History of Preaching, 6 . 
Swank asevera, "desde el principio, la predicación era vista como parte de una conversación llevada a cabo por todo el pueblo de Dios". ${ }^{9}$ Encontramos un ejemplo de este proceso de diálogo operando al comienzo de la vida de Jesús. El evangelista Lucas registra que cuando Jesús escuchó los discursos de los maestros en el templo, les hizo preguntas (Luc 2:46). El verbo usado aquí, eparōtaō, significa "consultar", "inquirir", "hacer una pregunta". ${ }^{10} \mathrm{El}$ contexto sugiere, estaba ocurriendo un proceso de diálogo, en lugar de hacerse una sola pregunta. Al parecer, el diálogo no solo era permitido, sino bienvenido, incluso de un joven oyente en la audiencia.

El evangelista Marcos comienza su relato del ministerio de Jesús con una lacónica, pero conmovedora, observación: "Jesús se fue a Galilea proclamando el evangelio del reino de Dios" ${ }^{11}$ Robert Mounce observa “estamos preparados para el protagonismo de la predicación en el ministerio de Jesús, porque él mismo declara que esta era la razón por la cual él había venido (Mar 1:38)". ${ }^{12}$ En un sentido muy real, toda la vida de Jesús fue un acontecimiento de predicación. Él era el Verbo de Dios encarnado. Nunca fue más cierto el dicho de

${ }^{9}$ Swank, Dialogic Style in Preaching, 47-48.

${ }^{10}$ Henry George Liddell and Robert Scott, A Greek-English Lexicon, 9th ed. (Oxford: Clarendon Press, 1996), 618.

${ }^{11}$ Mar 1:14. See also Mat 4:17, 23; 9:35; 11:1; Mar 1:38, 39; Luc 4:44; 8:1.

${ }^{12}$ Robert H. Mounce, The Essential Nature of New Testament Preaching (Grand Rapids: Wm. B. Eerdmans Publishing Company, 1960) 29. 
Marshall McLuhan que cuando declaró que en la vida de Jesús: "el medio es el mensaje". ${ }^{13}$

Jesús no predicó solo un sermón encarnacional. El estilo de su predicación también tenía una forma verbal diferente. Como ha observado Lloyd Perry, el estilo de predicación de Jesús era interactivo:

Jesús predicó algunos sermones parecidos al modelo de nuestros sermones convencionales que hoy se predican. De unos 125 incidentes registrados en los evangelios, en donde Jesús se comunicó con las personas, alrededor del 54 por ciento fueron iniciados por la audiencia. Su comunicación se caracterizaba por una conversación con preguntas y respuestas, objeciones, debate, concordancia y rechazo. ${ }^{14}$

Brian Greet está de acuerdo al hacer esta observación: "Los evangelios están llenos de diálogo, no de largas homilías brillantes". ${ }^{15}$ Jesús asumía el evento de la predicación como un diálogo, en vez de un monólogo. Él demostró una clara intención de escuchar a sus oyentes, antes de comenzar a hablar, durante el evento de la predicación y después de concluido el discurso. Al describir el impacto de la predicación de Jesús, T. Harwood Pattison, en The History of the Christian Preaching, señala: "La

${ }^{13}$ Marshall McLuhan, Understanding Media: The Extensions of Man (New York: McGraw-Hill Book Company, 1964) 7.

${ }^{14}$ Lloyd M. Perry, Biblical Preaching for Today's World (Chicago: Moody Press, 1973) 96. Estos datos fueron presentados en un trabajo anterior inédito como Tesis de Maestría: Albert M. Windham, "Preaching Is Not a OneMan Show", presentado en el Wheaton College Graduate School, 1969, 42.

${ }^{15}$ Brian A. Greet, "Dialogue Preaching", The Expository Times 78 (February 1967) 150. 
inmensa influencia ejercida por los discursos de Jesús es explicada aún más si consideramos cuan profundamente estaba interesado el predicador en sus oyentes" ${ }^{16}$

Aquí, el sermón de Jesús en la sinagoga de Nazaret es un buen ejemplo de esto. Jesús siguió la costumbre judía de estar de pie, mientras la Escritura era leída y luego sentarse para la interpretación. El registro de Lucas sugiere que la exposición fue sumamente breve: "Hoy se ha cumplida esta Escritura ante vosotros"(Luc 4:21). Sin embargo, la respuesta de los oyentes nos llevaría a una conclusión diferente: "Todos hablaban bien de él y estaban maravillados de las palabras de gracia que salían de su boca" (4:22). Al parecer, Jesús expuso sobre este tema, "con palabras llenas de gracia" y dejó el comentario grabado como el único pensamiento dominante en sus mentes. El registro de las Escrituras deja en claro que Jesús estuvo muy atento a la retroalimentación verbal y no verbal de su público. Sintiendo el escepticismo de sus oyentes, Jesús les dijo: “Seguramente me dirán el proverbio: 'Médico cúrate a ti mismo'" (4:23). Hay varios casos más registrados en los Evangelios donde Jesús demostró una sensibilidad a la retroalimentación del oyente. En una ocasión, cuando Jesús estaba predicando en un ambiente formal en la sinagoga de Capernaúm, su sermón fue interrumpido por un hombre poseído por un demonio. Marcos no revela el contenido del discurso de Jesús, sino que simplemente señala: "La gente estaba asombraba de su enseñanza, porque les enseñaba como quien tiene autoridad y no como los maestros de la ley"(Mar

${ }^{16}$ T. Harwood Pattison, The History of Christian Preaching (Philadelphia: American Baptist Publication Society, 1903), 22. 
1:22). Jesús estaba conectado con sus oyentes. Y este es un ejemplo de la predicación bíblica relevante en su mejor momento. De repente, un endemoniado en la audiencia ofreció cierta información verbal, con la exclamación sorprendente: “QQué quieres de nosotros, Jesús de Nazaret? ¿Has venido a destruirnos? Yo sé quién eres - el Santo de Dios"! (1:24).

En este momento, Jesús está procesando tanto la retroalimentación verbal como la no verbal. La retroalimentación verbal está viniendo de un espíritu maligno que está tratando de interrumpir el evento de la predicación y obstaculizar el ministerio de Jesús. La retroalimentación no verbal proviene de dos fuentes: la demoníaca, cuyo ser entero está implorando por libertad; y el resto de los oyentes, cuyo lenguaje corporal demuestra que ellos están esperando ansiosamente para ver cómo Jesús va a responder a esta situación.

¿Qué opciones estaban disponibles a Jesús en este momento? Podría haber ignorado los gritos de su oyente, pedido que este hombre incontrolado fuera echado de la sinagoga, y continuado su sermón. En cambio, Jesús reconoce esta interacción como una parte esencial del evento de la predicación. Note la respuesta decisiva de Jesús: “Cállate”, dijo Jesús severamente. 'Y sal de él!' (1:25) “Su interacción con el espíritu maligno es concisa y autorizada. Como resultado, el espíritu malo fue expulsado. Marcos no registra el diálogo verbal y no verbal que se produjo entre Jesús y el hombre liberado. Él simplemente registra la respuesta de la audiencia: "Y toda la gente estaba tan asombrada que todos se preguntaban unos a otros: '¿Qué es esto? ¿Es esta una nueva enseñanza que, con autoridad, manda aun a los espíritus inmundos y le obedecen?'" (1:27). El verbo suzēteō, traducido como "en duda", implica "exa- 
minar con, juntos"17 o "realizar una discusión" ${ }^{18}$ Una vez más, no hay ninguna indicación de que Jesús tratara de silenciar la interacción de su oyente, a fin de continuar con su sermón. Más bien, Jesús aceptó esta interacción como un componente valioso e integral del evento de la predicación.

En otra ocasión, Jesús estaba predicando a una multitud de varios miles de personas. El foco de su sermón era el peligro de la hipocresía y la certeza del juicio final. Mientras Jesús estaba predicando, alguien del público habló. Este oyente, preocupado con su propia agenda, dio una respuesta verbal que no tenía ninguna relación con el tema del sermón de Jesús. Quería que Jesús resolviera una disputa de herencia. La respuesta inicial de Jesús, según lo registrado por el evangelista Lucas, parece bastante grave: "Hombre, ¿quién me nombró a mí juez o árbitro entre ustedes?" (Luc 12:14). Sin embargo, pese a la interrupción aparente, Jesús era claramente atento a la retroalimentación no verbal del resto de la audiencia. Mientras ellos están impactados por la audacia de este hombre, su lenguaje corporal revela que están interesados en el tema en cuestión. En respuesta a esta retroalimentación, de la audiencia, Jesús realmente cambia el enfoque de su sermón. Su siguiente comentario se dirige no solo a la persona frente a él, sino a toda la audiencia.

${ }^{17}$ Gerhard Kittel, Theological Dictionary of the New Testament, ed. Gerhard Friedrich, vol. 7, trad. y ed., Geoffrey W. Bromiley (Grand Rapids: Eerdmans, 1971), 747.

${ }^{18}$ Walter Bauer, A Greek-English Lexicon of the New Testament and Other Early Christian Literature, 4th ed., trans. William F. Arndt and F. Wilbur Gingrich (Chicago: University of Chicago Press, 1957), 783. 
Lucas registra: “Entonces él les dijo a ellos: '¡Cuidado!' Guardaos de toda avaricia; la vida del hombre no consiste en la abundancia de sus bienes'" (12:15, énfasis añadido). Este comentario de Jesús es claramente relevante para el individuo que había "interrumpido" su sermón. Sin embargo, Jesús se basa en esta interacción y se dirige a todo el público con respecto al problema de la codicia.

Esta respuesta de Jesús, a la interacción verbal de un oyente, no se limita a un comentario ocasional. Él comparte luego la parábola de un rico necio, a fin de aplicar su punto. Para Jesús, la predicación no era simplemente la entrega de una colección anticipada de palabras e ideas. Más bien, la predicación era la comunicación de dos vías. La predicación involucraba interacción y diálogo. Predicación que requería una cuidadosa atención de parte de los oyentes.

El estilo de predicación de Jesús tuvo un efecto formativo sobre la predicación de los primeros cristianos. Lloyd Perry observa: “Los apóstoles también participan en la predicación multilateral. Ellos discutieron en las sinagogas (Hec 17:17; 18: 4) y 'en el razonamiento diario' en la escuela de Tirano (Hec 19: 9). A partir de un estudio de los sermones de estos hombres, deducimos que los auditores eran libres para interactuar con ellos" ${ }^{19}$ (2)

${ }^{19}$ Perry, Biblical Preaching for Today's World, 96. 